\title{
Caminhos da distopia no romance contemporâneo: a espera sem horizontes do individualismo niilista
}

\author{
Ways of dystopia in the contemporary novel: \\ expectations without hope of the nihilistic individualism \\ Caminos de la distopía en la novela contemporánea: \\ la espera sin horizontes del individualismo nihilista
}

Ângela Maria Dias ${ }^{*}$

\section{Resumo}

Peter Sloterdijk, ao caracterizar o individualismo "pós-social" da contemporaneidade para descrever o que considera o niilismo pós-moderno, apresenta um tipo de homem que renuncia à continuidade por meio da procriação e da transmissão da herança, em nome de seus próprios privilégios, numa espiral de egoica autossatisfação. O romance Heranças, de Silviano Santiago (2008), em sua contracena de pastiche e rebaixamento com o célebre Memórias póstumas de Brás Cubas, de Machado de Assis (1880), ao replicar o personagem machadiano na figura petulante de Walter, encena com requintes esta nova humanidade. A conduta cínica que o singulariza, gravada no estilo de sua narrativa autoconsciente, constitui a mais genuína encarnação da "falsa consciência esclarecida". Isto porque, a saga deste "réu confesso", após uma existência infecunda, consuma a sinergia da ambição pessoal com os imperativos de um sistema econômico corrupto e injusto. Nesse sentido, Heranças, pela voz de seu narrador e pseudoautor, e pela emulação que esta representa diante da dicção do inesquecível "defunto-autor" machadiano, reelabora a assepsia da estilística machadiana, rebaixando-a a uma dicção exibicionista de cafajeste.

Palavras-chave: distopia, individualismo, cinismo.

\begin{abstract}
In characterizing contemporary individualism as "post-social", in order to describe what he considers postmoderm nihilism, Peter Sloterdijk presents a kind of man who rejects the advancement of his bloodline in favor of his own privileges, in an extreme self-centeredness. The novel Heranças (2008) by Silviano Santiago, in its pastiche of the well-known Memórias póstumas de Brás Cubas (1880) by Machado de Assis, elegantly stages this new vision of humanity through the protagonist Walter. His cynical attitude, captured through self-conscious narrative, embodies the most genuine incarnation of Sloterdijk's "englightened false consciousness." This occurs, to the extent that this "confessed culprit" is able to arrive at a certain synergy between his personal ambitions and the injunctions of an economic system that is corrupt and unfair. In this way, Heranças recapitulates the aseptic style of Brás Cubas through Walter's voice and his vulgar tone.
\end{abstract}

Keywords: dystopia, individualism, cynicism.

\begin{abstract}
Resumen
Peter Sloterdijk, al caracterizar el individualismo "postsocial" de la contemporaneidad, para describir lo que considera el nihilismo postmoderno, presenta a un tipo de hombres que renuncian a la continuidad por medio de la procreación y de la transmisión de herencia, para garantizar sus propios privilegios, en una espiral egocéntrica de satisfacción personal. La novela Herencias (2008), de Silviano Santiago, en su juego de pastiche y degradación con la célebre Memorias póstumas de Brás Cubas (1880), de Machado de Assis, al replicar el personaje machadiano en la arrogante figura de Walter, escenifica con elegancia esta nueva humanidad. La conducta cínica que lo singulariza, grabada en el estilo de su narrativa autoconsciente, constituye la más auténtica encarnación de la "falsa consciencia esclarecida". Eso se explica porque la saga de ese "reo confeso", después de una existencia infecunda, representa la sinergía de la ambición personal con los imperativos de un sistema económico corrupto e injusto. En ese sentido, la novela Herencias, a través de la voz de su narrador y pseudo-autor, y debido a la
\end{abstract}

\footnotetext{
* Doutora em letras e professora da Universidade Federal Fluminense (UFF), Niterói, RJ, Brasil. (Dorcid.org/0000-0002-2464-8907. E-mail: angelmdias@gmail.com
} 
emulación que esta representa frente a la dicción del inolvidable "difunto-autor" de Machado de Assis, rehace la asepsia del estilo machadiano y la rebaja a una dicción exhibicionista de canalla.

Palabras clave: distopía, individualismo, cinismo.

Peter Sloterdijk (1999, p. 87), ao caracterizar o individualismo "pós-social" da contemporaneidade, refere-se à metáfora das "ilhas nomadizantes" para descrever o que considera uma "terceira insularização" da humanidade que "tanto produz quanto reivindica uma grande medida de privilégios sociais como pressuposto para a renúncia" à própria tarefa da autorreprodução, isto é, da continuidade por meio de procriação e da transmissão da herança. Esta descontinuação antropológica vista pelo filósofo como "crise da paternidade e do princípio genealógico" tem a ver com a transformação do indivíduo numa espécie de "míssil, a caminho em seu próprio cosmo" (Sloterdijk, 1999, p. 87) ou ainda com sua destinação a uma vivência "como consumidor final de si mesmo e suas chances" (Sloterdijk, 1999, p. 88-89).

O romance Heranças, de Silviano Santiago (2008) em sua contracena de pastiche e rebaixamento com o célebre Memórias póstumas de Brás Cubas, de Machado de Assis (1880), "mineiriza" a figura do celibatário rico, hedonista e egocêntrico pela adoção de uma moral de cafajeste que, numa operação de agressiva antropofagia, replica o personagem machadiano na figura petulante de Walter, que na espera da própria morte, após uma existência perdulária e infecunda, sai em busca de um herdeiro.

O cinismo do estilo não ilustra apenas o perfil moral do personagem-narrador, mas também é responsável pela ironização geral de todas as condutas, tanto na ação quanto na sua enunciação teratológica; quando o falante nunca está no que diz ou ainda quando, num outro extremo paradoxal, o narrador se revela e se autodeprecia numa descarada franqueza capaz de comprazer-se com o próprio egocentrismo, a exemplo da insigne ascendência inaugurada por Diderot, o filósofo-autor de $O$ sobrinho de Rameau.

Assombrado pela decadência física na antessala da morte, desde as primeiras páginas destas memórias ficcionais, o narrador-personagem - desdobrado em “juiz-penitente" (Santiago, 2008, p. 117), pelo autoespelhamento da escrita de si - é o retrato do que Sloterdijk (2012, p. 34) considera a "falsa consciência esclarecida", não se poupando da prática de baixezas pela vida afora, na autoconsciente busca de capital e de status, em sua bem-sucedida trajetória de ascensão social.

Nesse sentido, o dilaceramento do "réu confesso" (Santiago, 2008, p. 97) em sua jocosa autoexposição não passa pela "tragédia de uma consciência infeliz" (Safatle, 2008, p. 56), mas como um Brás Cubas ainda não desencarnado, em seus desplantes, pontua a cada momento sua superioridade de acrobata e hábil manipulador de aparências, junto ao leitor. Desvela seus truques e trapaças, "com verdades nuas, que mantêm algo falso no modo como são expostas" (Sloterdijk, 2012, p. 26), e desfila sua volubilidade exibicionista à semelhança do precursor machadiano, na medida em que se esmera no consumo acelerado de posturas e papeis sociais, pela ligação visceral às transformações do capitalismo brasileiro no decorrer de sua existência. Assim, a industrialização de uma Belo Horizonte provinciana o conduz, sem hesitação, à primeira e bem-sucedida guinada profissional:

Buscaria contato asséptico com o dinheiro e a mercadoria lucrativa, evitando a intermediação do gênero humano. No minuto de compra e venda, quanto menos concreta for, mais eficiente é a moeda corrente. Quanto mais abstrato for, maior é o valor do capital. Queria imitar os grã-finos que, nomeados em palavras, apareciam em fotos e tinham a atuação política e econômica descrita na coluna social de Wilson Frade. Eu seria um deles. Sem rosto, é claro, pois detestava minha foto em jornal. Ao manipular com inteligência e imaginação os lucrativos negócios da construção civil, ancoraria o nome Ferreira Ramalho lado a lado dos outros grandes nomes metropolitanos, que já ocupavam espaço em O Estado de Minas (Santiago, 2008, p. 91). 
Assim, o "sentimento íntimo do tempo e do país" do Machado de Assis (1980, p. 357) crítico no Instinto de nacionalidade igualmente imprime sua marca na narrativa do niilismo pós-moderno de Walter, pela sinergia do capricho e das ambições pessoais com a evolução econômico-financeira do país:

Em termos gerais, a sinergia redundou no atalho que me levou, da soma comercial ao deslumbramento diante da multiplicação imobiliária e, do deslumbramento industrial, ao delírio reservado aos poucos que robustecem o mercado de capitais. Ou seja, ela é o atalho que me fez ir - no tempo-espaço da vida humana - da ideia linear de comprimento à ideia de lucro por área para, desta, saltar à de acúmulo do capital por volume (Santiago, 2008, p. 134).

Por outro lado, a veleidade do foco narrativo, na construção de um enredo pontilhado por anedotas, parábolas, pequenos causos, digressões ociosas e frequentes interpelações ao leitor, constrói um enredo sem grandes conflitos, capaz de, sem delongas, contornar impasses e rivalidades no percurso do personagem-narrador, pela via de uma torpeza eficiente e confessada entre subterfúgios e negaceios. A voz arbitrária e ladina de Walter, dessa maneira, combina o solo de um desabrido cinismo com contrapontos estridentes de um humor escatológico e rebaixado, combinado a esdrúxulos paralelismos melodramáticos no comentário de situações e personagens. Nessa dimensão, o pastiche de Memórias póstumas não poderia ser mais evidente. Como já o constatou Roberto Schwarz a respeito da obra prima de 1880, "a conversa miúda e as grandes abstrações formam na prosa machadiana uma inseparável dupla de comédia" (Schwarz, 1990, p. 51).

E como o histrionismo também configura a errância estilística de Heranças, não é à toa que as epígrafes do romance, constituídas entre raspas da oralidade, reúnem uma "frase escutada num bar do mercado municipal de Belo Horizonte" - "Quem tem irmão não precisa de inimigo" - e um provérbio espanhol simultaneamente irônico e escatológico - "El papel todo lo aguanta; hasta que se limpien con él" - como abertura de um capítulo igualmente escatológico, no qual o autor, em tom irônico, de chofre, anuncia: "Elegi a cidade, escolhi o cemitério. Decidi passar os últimos anos de vida no Rio de Janeiro e ser enterrado no S. João Batista" (Santiago, 2008, p. 7).

A escatologia acompanha o memorialismo na medida em que as confissões canalhas constituem o âmago do exercício nu do arbítrio e da manipulação deste narradorpersonagem que, em pleno século XXI, atualiza o reverso desrazoável da razão, já surpreendido por Hegel no Rameau de Diderot ${ }^{1}$ e, entre nós, soberanamente encenado pelo precursor de todos os cínicos na literatura brasileira, o Brás Cubas de Machado. Nesse sentido Walter sinaliza bem a "metamorfose ambulante" desses incorrigíveis protagonistas da volubilidade. Não é à toa que a respeito do pai de todos os cínicos na modernidade, dramatizado pelo filósofo iluminista, Rubens Torres Filho chegue a declarar:

O cínico adere a seu discurso a tal ponto que não mente: não fala contra a verdade, pois não fala em nome dela; não é moral nem imoral, pois não opera sobre o pressuposto dessa distinção, não é hipócrita: não esconde seu ser verdadeiro, pois não é nada, 'no fundo', não tem nenhuma essência (Torres Filho, 1987, p. 58).

A nossa atual contrapartida a esta patologia diagnosticada em pleno alvorecer da razão ilustrada, em seu momento de autocrítica, talvez tenha sido formulada por Lyotard (1987, p. 19), quando afirma que "o ecletismo é o grau zero da cultura contemporânea", referindose ao estatuto atual da arte, num momento em que "a questão estética moderna não é: o que é belo, mas: o que é arte (e literatura)?" (Lyotard, 1987, p. 18).

Na medida em que reconhece a desrealização corrente dos objetos humanos, papeis da vida social e instituições, promovida pelo capital (Lyotard, 1987, p. 16), o filósofo da pósmodernidade desenha um quadro de indeterminação perfeitamente compatível com o que Sloterdijk compreende desde 1983, por "razão cínica".

\footnotetext{
${ }^{1}$ Trata-se de uma alusão à Fenomenologia do espírito, onde o filósofo dedica um capítulo à discussão de $O$ sobrinho de Rameau de Diderot, para refletir sobre o cinismo como o outro lado de razão ilustrada. A respeito deste diagnóstico, entre outros filósofos brasileiros, Rubens Rodrigues Torres Filho (1987) e Vladimir Safatle (2008) debruçam-se em comentários esclarecedores.
} 
Nesse sentido o ecletismo - ou seja, a indiferença distanciada e/ou a adesão despojada a toda e qualquer prática ou valor - equivale, na vida cotidiana das grandes cidades, ao cinismo hoje corrente como sintoma do estatuto do saber, no cenário da atual informatização das sociedades (Lyotard, 1987, p. 17). É que, imersas numa crise de legitimação e incapazes de produzir expectativas de valoração universalizantes, tais sociedades, incrédulas em relação aos metarrelatos, em decorrência da hegemonia das ciências e dos critérios tecnológicos de operatividade, não têm mais como decidir sobre o que é justo ou verdadeiro (Lyotard, 1987, p. xvi-xvii).

Assim, a partir da decomposição dos grandes relatos, a reordenação das coletividades sociais coloca os indivíduos "numa textura de relações mais complexa e mais móvel que nunca" caracterizada pelos "jogos de linguagem" como um novo tipo de vínculo social, no qual a performance comunicacional ganha importância decisiva por seu caráter eminentemente agonístico (Lyotard, 1987, p. 28-29) e exigente, no que tange a uma necessária diversificação do saber, a partir de uma espiral de versatilidade, em que a especialização moderna deve trocar-se por "uma formação considerável de competências" (Lyotard, 1987, p. 36).

Não é à toa que, por sua vez, a argúcia de Walter, em sua habilidade intuitiva, sintoniza, apesar da escolaridade insuficiente, o pragmatismo e a adaptabilidade exigidos pelas transformações do capital. De início, o aprendizado avulso pela via amorosa:

Sou o autodidata que, repetidas vezes, me espelhei nas mulheres com quem transei e convivi, para delas furtar, como moderno Prometeu, o fogo do saber. [...] Cada uma de minhas deusas, a sua maneira, foi minha professora. Minhas variadas amantes, meu variadíssimo saber (Santiago, 2008, p. 37).

Mais adiante, a afinada sincronia do ouvido musical que faz o personagem "ter dançado a música da vida de acordo com os sucessivos ritmos da moda" (Santiago, 2008, p. 346), se configura num impudico pastiche do autor Silviano Santiago sobre a teoria machadiana da errata humana, que o bruxo, por sua vez, rouba a Pascal (Assis, 1962, p. 75). Entretanto, o tom sarcástico inerente à releitura do século XXI, opera sempre um rebaixamento da sentenciosidade do mestre, em maior ou menor grau, conforme a ocasião. Aqui, a errata é trocada, primeiro, pelas regras do futebol e depois, pela ninharia da "tomada de abajur":

Sou como tomada de abajur. Adapto-me a todas as voltagens. Com minha ajuda, o abajur permanece ligado e útil. Vez ou outra, mudo a lâmpada para que, ao ser acesa, não se queime. O leitor amigo já imaginou: a tomada sou eu, o abajur, meu caráter imutável e a lâmpada, as várias e sucessivas ideias alheias, que serviram para compor meus perfis provisórios (Santiago, 2008, p. 347).

Aliás, a antropofagia de mestre Machado, continuada no romance Machado (2016) uma espécie de "alterficção" capaz de misturar os últimos anos do escritor celebrado e do próprio Silviano - aqui neste romance debochado, encontra também sua justificativa na própria tagarelice do personagem-narrador:

Quem bem faz só para si faz. No novo milênio, o valor da moeda reproduz o valor da terra nos primórdios da civilização brasileira. Sorte minha, sorte nossa, se os novíssimos tempos se assemelham aos velhos tempos (Santiago, 2008, p. 352).

O egoísmo e a franqueza sem peias, estilizada pelo tom exibicionista, são os mesmos do solteirão defunto de 1869. A autointitulada "Moral de monjolo" do celibatário mineiro, se multiplica em muitas outras variantes e começa a delinear-se desde a abertura de ambos os relatos, com a invocação dos vermes, na hora do enterro. Como é sabido, nas Memórias póstumas, a dedicatória de Brás Cubas é espantosa e impertinente: "Ao verme que primeiro roeu as frias carnes do meu cadáver" (Assis, 1962). Em Heranças, na antecipação fantasiosa da cerimônia fúnebre, Walter se refere ao "bando buliçoso dos vermes que põem a cabecinha de fora para se alimentar com o inesperado jantar servido em madeira de lei" (Santiago, 2008, p. 15).

Aliás, a morte, à semelhança de seu modelo célebre, é também o grande baixo contínuo desse romance desabusado. A sua abertura já aponta as escolhas deliberadas para a espera do momento final: "Elegi a cidade, escolhi o cemitério. Decidi passar os últimos anos de vida no Rio de Janeiro e ser enterrado no S. João Batista" (Santiago, 2008, p. 7). 
Já o segundo capítulo, continuando a cena do primeiro, com o mineiro, recém instalado em Ipanema, alude indiretamente ao móvel subjacente que, desencadeado pelo relato, vai movimentar a vida do narrador idoso, a inexistência de herdeiros:

Escapei-me do provérbio que reza: "Quando Deus não dá filhos, o diabo dá sobrinhos". Não tive filhos. Não tenho sobrinhos. Tive muitas amantes. [...] Dividi-me entre inumeráveis amantes, sem me dividir em outro ser, meu filho. Como sovina não é adepto dos modernos planos de saúde e religioso, dos anticoncepcionais, não o sou da procriação humana. Questão de direitos daquele que inocula. Se não há essa cláusula na Declaração dos Direitos do Homem e do Cidadão, que o majestoso Povo Francês a inclua. [...] Se procriar foi ato de fraqueza no século 20 do holocausto judaico, das bombas atômicas arrasacidades e da AIDS, mais será no milênio que se abre pela fome milenar dos povos desenvolvidos e por guerras religiosas fundamentalistas. Em terra de gavião, galinha não vinga pinto, já diz o ditado (Santiago, 2008, p. 17-18).

A recusa da própria descendência, característica da insularização contemporânea, de início mencionada, entretanto, no caso deste narrador capcioso, não se estende à transmissão da herança. Se não há qualquer preocupação de Walter com o aspecto existencial e formativo do legado, o fato é que, "a febre da rememoração (que) irrompeu e tomou conta de (seu) cotidiano ipanemense" (Santiago, 2008, p. 172) vai levá-lo a uma atitude que poderia ser considerada, dado o seu caráter, uma última e audaciosa esperteza, ou ainda, um derradeiro golpe de mestre.

A interface entre o projeto narrativo do protagonista de Heranças e o do seu ancestral machadiano, nos leva a tal hipótese. Nesse sentido o legado de Walter a um insuspeito destinatário, seria uma espécie de suplemento ao antológico último capítulo do Memórias póstumas: o "Das negativas". Do nosso ponto de vista, tudo a ver com a ousadia antropofágica de Silviano diante da reconhecida excelência de seu espelho literário.

A aventura do autodesvendamento da vida leva o narrador-personagem, em sua pretensão, a autoapelidar-se de Jean-François Champollion, o egiptólogo que traduziu o decreto de Ptolomeu, inscrito na pedra de Roseta. E, nesse sentido, a compreensão progressiva do passado remoto "como um texto escrito em hieróglifos" (Santiago, 2008, p. 16) vai conduzindo Walter à constatação do vazio da própria vida:

Exaurida a água do poço que por meses desalterou a sede da imaginação, ofertandolhe mais e mais frases, meus pensamentos se voltam para a atual imobilidade do corpo e da mente no apartamento da avenida Vieira Souto. [...] O presente ipanemense deixa de ser o que tem sido - laborioso e fascinante. Tornou-se o que nunca deveria chegar a ser - cópia do vazio infinito da existência (Santiago, 2008, p. 364).

A este respeito, Luiz Costa Lima (1981, p. 64), num artigo intitulado "Sob a face de um bruxo", comenta que "em Machado a pedra de toque (para a criação ficcional) são a presença da morte e da esterilidade, nomes que nele com frequência indicam a presença do vazio".

Assim, no transcorrer de suas recordações inconfessáveis, o autonomeado "filhinho do papai" depara-se com "o vazio infinito da vida (que) se confunde com o obstáculo que o majestoso Pico Dois Irmãos representa para o observador". Ou seja, o obstáculo deve ser transformado em túnel, já que o desbravador das gerais, depois do esgotamento das memórias, se impõe a tarefa de "dar continuidade ao presente". E para isso, "o túnel a ser desbravado e aberto sob o pico" deveria superar o impasse com que se depara o memorialista: "Não tenho a quem - de nome preciso deixar todas as minhas posses. E são incontáveis" (Santiago, 2008, p. 47, p. 364-365).

$\mathrm{Na}$ antessala da morte, o narrador prevenido e matreiro, busca melhor coroar o momento final, por meio de mais uma jogada de mestre. Afinal, para o autossuficiente Walter, "a bola é a palavra" (Santiago, 2008, p. 126), no comércio da vida e na esgrima com o leitor. Se, no caso de Machado de Assis, a emulação chega à concepção relacional da obra de arte pela literatura de Sterne (Lima, 1981, p. 63), aqui, o exemplo machadiano da conversa entre autor e leitor é levado às últimas consequências da derrisão, por vezes beirando o grotesco, na mescla estilística entre o escatológico e o rebuscado. 
Ou seja, em outras palavras, Heranças reelabora a assepsia estilística machadiana, rebaixando-a a uma dicção exibicionista de cafajeste. Nesse sentido, constitui o epitáfio de Walter a seus leitores, radicalizando a "Filosofia dos epitáfios", de um dos capítulos finais das Memórias que os compreendem como "uma expressão daquele pio e secreto egoísmo que induz o homem a arrancar à morte um farrapo ao menos da sombra que passou" (Assis, 1962, p. 269).

A jogada de mestre desse audacioso "dono da bola", em busca de quem, em seu nome a receba e constitua “a aurora para o capital acumulado" (Santiago, 2008, p. 127, p. 365), parte, evidentemente, também de uma releitura degradada da teoria da equivalência das janelas do escritor-defunto.

Afinal, como o próprio Walter trata de reconhecer, "a virtude não é menos ousada e menos desinteressada do que o vício e a paixão" (Santiago, 2008, p. 69). No caso de Brás Cubas, os motivos que o moveram a criar a teoria das compensações cínicas, são bem menos graves que os de Walter. Neste último, o artifício da herança trata de passar a limpo um episódio bastante torpe. No primeiro, "a lei sublime" equilibra pecados venais cometidos em nome do vazio da representação social.

Assim, de um lado, a tentação do adultério e, de outro, a devolução de uma moeda de ouro, encontrada ao acaso, acalentam a alma do narrador em seus desplantes. Ou seja, a dança compassada da esterilidade é, por vezes, criativa e, assim se concretiza a verdade caricata desta lei apaziguadora: a abertura de uma nova janela para equilibrar a rarefação da outra janela fechada pela culpa, "a fim de que a moral possa arejar continuamente a consciência" (Assis, 1962, p. 116).

As questões de Walter, como constataremos, levam a mesma esterilidade ao extremo do crime. Ou seja, em nome do valor maior da representação social, ou seja, do prestígio econômico e social, o narrador "solitário e autocentrado" decide livrar-se da irmã que, bem contemplada pelo testamento do pai, se havia então transformado em um empecilho à trajetória ambiciosa do herdeiro mal aquinhoado. Depois de uma série de intermináveis e cínicos preâmbulos e negaceios à confissão o narrador decide por fim revelar-se:

Velhice e verdade são palavras irmãs pela inicial. [...] Paro de escamotear. Morre o cavalo a bem do urubu. Na velhice ipanemense, ouso confessar a verdade. Minha verdade. Não tenho o intuito de contradizer-me, nem a intenção de apresentar-me como único culpado pela morte de Filinha. Confesso por confessar, do mesmo modo como, no interior de Minas, as mulheres debulham espigas de milho para alimentar galos e galinhas no terreiro. [...] Confesso. Estive metido de maneira em nada circunstancial no acidente com o Chevrolet. [...] O acidente fora premeditado e criminoso. Fora deliberado, portanto. Pelo menos de minha parte (Santiago, 2008, p. 105).

A força do relato leva o narrador a uma outra expansão que, logo em seguida, suspende:

A máscara mortuária de Filinha encontrou contraponto em minha máscara de dor e as duas - a primeira real e a outra possível - afiançavam minha inocência. Escapeime do xilindró. Caí em cheio noutro xilindró. Este relato confessional. Lembro-me. Calo a memória, susto o inquérito policial (Santiago, 2008, p. 107).

Em seguida, o narrador se esquiva, refugiando-se na paisagem das ondas do mar de Ipanema. Aqui a teoria da equivalência das janelas, no seu funcionamento subjacente, vai buscar por intermédio do relato-xilindró, a janela aberta para a alcova sufocante da confissão do assassinato. E surge assim, em meio ao esgotamento do dilúvio das memórias, a necessidade do herdeiro.

O resgate de Vitorino, o namorado pipoqueiro, pobre e corcunda da irmã Filinha, fornece então o contraponto grotesco, na remissão a Quasímodo, à farsa familiar encenada pela rejeição do pai aos planos de casamento da filha, e, mais adiante, pelo oportunismo criminoso de Walter diante da irmã bem aquinhoada.

De fato, a composição de Vitorino é carregada de tintas sádicas e mantém relações alusivas com a célebre obra de Victor Hugo, pela folhetinesca mistura entre a pureza de sentimentos do personagem e sua aparência lamentável. O exagero refinado da descrição é tal que chega a rebaixar, com delícia, a mistura do sublime / grotesco inerente à fórmula hugoana. E, no contexto em que se insere, certamente tinge sua verossimilhança com as tintas inusitadas do absurdo.

A corcunda acabou por ser o detalhe menos grotesco de Vitorino. Recoberta pelo paletó folgado, a deformidade física lhe emprestava a aparência de cantor de ópera 
italiano, cuja caixa toráxica tinha sido soprada pelos artesãos da ilha de Murano. Vitorino era dividido em duas partes contrastantes: cabeça e tronco bojudos repousavam em duas pernas finas. O corpo tinha as dimensões duma gigantesca licoreira de cristal. Uma licoreira gorducha, de cabeça voltada para baixo. Tinha os dois gargalos - as duas pernas - emborcadas no assoalho (Santiago, 2008, p. 164-165).

A apresentação da desmedida física prossegue e se conclui pela absolvição edulcorada do personagem transformado, por vias tortas, quem sabe, no clone ultrarromântico e rebarbativo da inesquecível Eugênia, "a flor da moita": "Por que bonita, se coxa? Por que coxa, se bonita?" (Assis, 1962, p. 84). Afinal, também Vitorino possuía suas belezas: "o sorriso aberto e envolvente - de dentes fortes e claros - (que) ganhava a todos pela bondade que exalava" e, por isso mesmo, é, em seguida considerado pelo narrador como "um puro" (Santiago, 2008, p. 165)

A referência imprevista deste narrador impertinente ao "xilindró" do relato, subitamente gerado pela "febre da rememoração", por sua vez, cria um interessante gancho para que possamos compreender a necessidade de redenção que compreensivelmente faz emergir. Assim, a "aurora do capital acumulado" (Santiago, 2008, p. 172, p. 365), antes do crepúsculo do seu possuidor, deveria ser presidida por um agente disposto a processá-la. O alvorecer é o extremo oposto da clausura.

Dessa forma, de um lado valida-se a lei das compensações cínicas e de outro, premia-se ainda e sempre "o dono da bola" (Santiago, 2008, p. 365, p. 127), a partir de uma outra e consoladora recorrência ao arsenal de parábolas de Brás Cubas. Trata-se agora, da "Teoria do benefício", narrada por Quincas Borba a Brás Cubas, quando o filósofo do Humanitismo assevera ao amigo que "o prazer do beneficiador é sempre maior que o do beneficiado", porque, no caso do segundo, "uma vez cessada a privação [...] é natural que a memória se esvaeça" (Assis, 1962, p. 266).

Nessa direção, é possível compreender-se a autojustificativa final do narrador quando conclui: "Eu tinha finalmente cumprido minha missão na terra. Podia morrer tranquilo e ter o corpo encaixotado em madeira de lei pela Funerária Botafogo" (Santiago, 2008, p. 397). Ou seja, a janela aberta pela busca e encontro de Vitorino, substitui risonhamente a morte da irmã e de seu filho, ainda em gestação. E assim possibilita que a espera da morte possa aliviar-se das pendências anteriores. Aliás, esta situação na qual o narrador prepara a própria morte, de certa forma, encena o próprio estatuto da autoria como "um espaço onde o sujeito que escreve não para de desaparecer" (Foucault, 2001, p. 32).

Não é à toa que Walter, o narrador-personagem do romance Heranças é o pseudoautor deste memorial e, por isso mesmo, vai inscrevê-lo num certo tipo de discurso, cuja "função autor é, portanto, característica do (seu) modo de existência, de circulação e de funcionamento [...] no interior de uma sociedade (Foucault, 2001, p. 274).

Nessa perspectiva, o espelhamento do romance Heranças de Silviano Santigo na correspondente pseudoautoria de Walter não é inocente. Se o autor, como pondera Foucault, em sua reflexão sobre o assunto, pode exceder a própria obra, no sentido de instaurar uma discursividade, ou seja, um conjunto de outros discursos analógicos e/ou diferentes em relação a ela; o próprio romance Heranças é, por si, uma dramatização deste efeito. Ele mesmo constitui mais uma partitura da colossal orquestra de dissonâncias gerada pela obra de Machado de Assis.

No seu desdobramento de pastiche abusado do defunto-autor, o romance do memorial de Walter replica também Aires, o velho conselheiro igualmente à espera da morte, e pode certamente atirar em outras direções ainda não observadas. Talvez por isso mesmo, o pseudoautor, ao final se manifeste, em sua imoderada imodéstia, inteiramente indiferente ao que venham a considerar sobre seus escritos:

Como pude apresentar-me como o Champollion das Gerais e, agora, estar a escrever um relato a ser decifrado e completado pela perspicácia e a imaginação do leitor? Bombardeio as más intenções expressas pelos laços de amizade entre bom senso e autocensura. Abre-se o jogo pelas regras do jogo. Não entregarei o manuscrito com rasuras. Certeza absoluta? Se estiver pensando o pior de mim, pouco me importa. Quando estas páginas forem liberadas à leitura, o cadáver responsável estará alimentando os vermes que, desde 1852 e sob o alto patrocínio da Santa Casa de Misericórdia da cidade do Rio de Janeiro, são engordados pelos sucessivos e saborosos inquilinos do Cemitério de S. João Batista (Santiago, 2008, p. 111). 


\section{Referências}

ASSIS, Machado de (1980). Instinto de nacionalidade. In: COUTINHO, Afrânio (Org.). Caminhos do pensamento crítico, v. 1. Rio de Janeiro: Pallas, p. 355-363.

ASSIS, Machado de (1962). Memórias póstumas de Brás Cubas. São Paulo: Edigraf.

FOUCAULT, Michel (2001). Estética: literatura e pintura, música e cinema. Tradução de Inês Autran Dourado Barbosa. Rio de Janeiro: Forense Universitária.

LIMA, Luiz Costa (1981). Dispersa demanda (ensaios sobre literatura e teoria). Rio de Janeiro: Francisco Alves.

LYOTARD, Jean-François (1987). O pós-moderno explicado às crianças. Tradução de Tereza Coelho. Lisboa: Publicações Dom Quixote.

SAFATLE, Vladimir (2008). Cinismo e falência da crítica. São Paulo: Boitempo.

SANTIAGO, Silviano (2008). Heranças. Rio de Janeiro: Rocco.

SCHWARZ, Roberto (1990). Um mestre na periferia do capitalismo. São Paulo: Duas Cidades.

SLOTERDIJK, Peter (1999). No mesmo barco: ensaio sobre a hiperpolítica. Tradução de Claudia Cavalcanti. São Paulo: Estação Liberdade.

SLOTERDIJK, Peter (2012). Crítica da razão cínica. Tradução de Marco Casanova, Paulo Soethe, Pedro Costa Rego, Maurício Mendonça Cardozo, Ricardo Hiendlmayer. São Paulo: Estação Liberdade.

TORRES FILHO, Rubens Rodrigues (1987). Ensaios de filosofia ilustrada. São Paulo: Editora Brasiliense. 